\title{
Postdocs call for better pay and conditions
}

Corie Lok, Washington

A meeting of postdoctoral researchers and their supporters in Washington last week failed to agree on how to improve pay and conditions. And some questioned whether there were too many postdocs chasing too few tenured positions.

The meeting, organized by the National Academies' Committee on Science, Engineering and Public Policy (COSEPUP), brought together more than 300 researchers, advisers, administrators and representatives of funding agencies and societies.

Their aim was to explore ways of taking forward recommendations made last year in the COSEPUP guide, Enhancing the Postdoctoral Experience for Scientists and Engineers.

Postdocs complained that they received inadequate stipends, poor (if any) mentoring, and little support from the administrators or tenured staff at their institutes.

Everyone agreed that change was needed, but not who should take responsibility for it.

"I was disappointed the funding agencies were so refractory to our suggestions by either not answering our questions or saying change was too difficult," said Mary O'Riordan, president of the Postdoctoral Association at the University of California at Berkeley.

Pay was the main concern. A starting salary for a life-sciences postdoc should be in the region of $\$ 35,000$ (some $\$ 10,000$ more

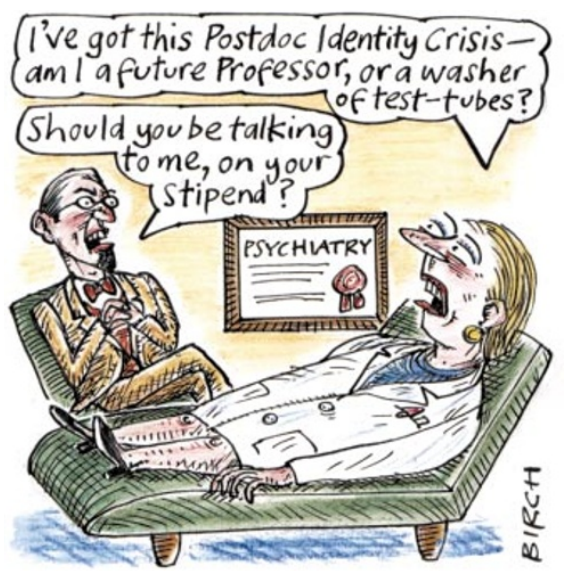

than at present) said Susan Gerbi, department chair of molecular and cell biology at Brown University in Rhode Island. Marvin Cassman, director of the National Institute of General Medical Sciences and representative of the National Institutes of Health (NIH, the largest supporter of postdoctoral research) agreed that a pay rise was needed.

The researchers called on institutions and funding agencies for help. They asked the NIH and the National Science Foundation (NSF), for example, to include mentoring skills as part of the grant proposal review. But NIH and NSF representatives said they could not enforce this - their role was simply to evaluate research outputs.
Postdocs should find out more before accepting posts, said Jonathan Yewdell, head of the cellular biology section of the National Institute of Allergy and Infectious Diseases. They could assess mentors by talking to people already working in their laboratories.

Institutions should provide supervision and services, said Cassman. At present only a few, such as the University of Pennsylvania School of Medicine, have dedicated offices handling postdoctoral issues. Some are not even sure how many postdocs they have.

"There's an absolute need for a postdoc office," says Tom Sweitzer, co-chair of the Postdoctoral Council at the University of Pennsylvania School of Medicine. "It's the key to solving $90 \%$ of the problems."

The researchers themselves questioned whether there were too many of them for the shrinking number of tenure-track positions.

"In the biological sciences, we've got to change our attitudes," says Elizabeth Ann Jones, a postdoc at the Uniformed Services University of Health Sciences in Maryland. "[Tenure] is not likely to happen for all of us."

As many postdocs are actually staff scientists hired to do bench work, one suggestion was to formalize this difference by creating a separate class of 'staff scientists'.

No further meetings have been scheduled yet. Maxine Singer, chair of COSEPUP, said: "We're hoping this will take off on its own". http://www.nap.edu/books/0309069963/html/

\section{Gene sequencers hope to put the bite on mosquitoes}

\section{David Adam}

The next creatures to have their genomes sequenced will be the laboratory rat and the mosquito chiefly responsible for spreading malaria in sub-Saharan Africa.

The plan to sequence the 260 million base pairs of the mosquito Anopheles gambiae was announced this week by a consortium of researchers and sequencing centres.

US company Celera Genomics and Genoscope, the French national sequencing centre, will carry out the initial sequencing using the whole-shotgun technique. They will break the genome into fragments and sequence the DNA of each piece; Celera will reassemble these into a full sequence. Other centres will help to finish and annotate it.

The team expects the project to cost less than $\$ 10$ million and be ready, as a rough draft, by the end of the year. The French government will part-fund the effort, and the consortium hopes that US agencies and the European Union will provide the rest.

Malaria infects three million people and kills one and a half million each year.
"The sequence will be enormously valuable," says Steven Sinkins, who studies mosquito genetics at the Liverpool School of Tropical Medicine. "It will transform what we can do on a molecular genetics level."

It will help researchers find genes that let mosquitoes carry and transmit the malaria parasite, he predicts, as well as shedding light on insecticide-resistance. Many traits have been loosely traced to genome regions, but Sinkins says the new work should let researchers focus on individual genes or particular metabolic pathways.

The rat genome - containing an estimated three billion base pairs, similar to the human genome - will be sequenced by Celera Genomics and the Baylor College of Medicine, Houston, sharing a \$58 million grant from the US National Institutes of Health. They aim to finish in two years.

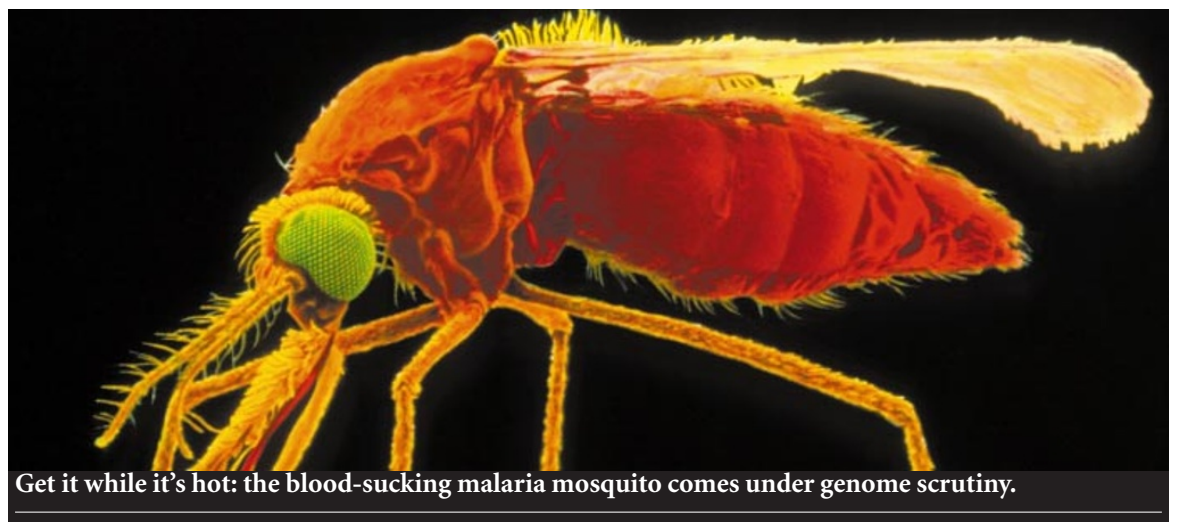

